NBER WORKING PAPER SERIES

\title{
WHO HAS A BETTER IDEA? INNOVATION, SHARED CAPITALISM, AND HR POLICIES
}

\author{
Erika Harden \\ Douglas L. Kruse \\ Joseph R. Blasi \\ Working Paper 14234 \\ http://www.nber.org/papers/w14234
}

\author{
NATIONAL BUREAU OF ECONOMIC RESEARCH \\ 1050 Massachusetts Avenue \\ Cambridge, MA 02138 \\ August 2008
}

Presented at the Russell Sage/NBER conference in New York City, October 2006. We thank Katherine Klein and other participants for valuable comments. This research is supported by a grant from the Russell Sage Foundation and the Rockefeller Foundation. The National Opinion Research Center at the University of Chicago provided valuable assistance with the General Social Survey segment that forms the basis for some of the analysis. Refen Koh, Rhokeun Park, Michelle Pinheiro, and Patricia Berhau provided excellent assistance in survey scanning, entry, and verification. The views expressed herein are those of the author(s) and do not necessarily reflect the views of the National Bureau of Economic Research.

NBER working papers are circulated for discussion and comment purposes. They have not been peerreviewed or been subject to the review by the NBER Board of Directors that accompanies official NBER publications.

(C) 2008 by Erika Harden, Douglas L. Kruse, and Joseph R. Blasi. All rights reserved. Short sections of text, not to exceed two paragraphs, may be quoted without explicit permission provided that full credit, including $\odot$ notice, is given to the source. 
Who Has a Better Idea? Innovation, Shared Capitalism, and HR Policies

Erika Harden, Douglas L. Kruse, and Joseph R. Blasi

NBER Working Paper No. 14234

August 2008

JEL No. J33,J54,L23,L25

\begin{abstract}
We investigate the relationship of "shared capitalist" compensation systems - profit/gainsharing, employee ownership, and stock options - to the culture for innovation and employees' ability and willingness to engage in innovative activity. Using a large dataset with over 25,000 employee surveys in over 200 worksites of a large multinational organization, we find that both shared capitalism compensation and high performance work policies contribute to these innovation outcomes. Owning company stock is the most consistently positive compensation variable in predicting both an innovation culture and willingness to engage in innovative activity. We also find that shared capitalism and high performance work policies have stronger effects in predicting an innovation culture when they are combined, and that the effects of shared capitalism and high performance work policies are partially, but not wholly, mediated through greater employee alignment with company strategy. The findings are consistent with agency theories predicting that the principal agent problem can be addressed by a combination of shared incentives and cooperative culture which encourages mutual monitoring and opportunities to share information.
\end{abstract}

\author{
Erika Harden \\ Rutgers University \\ 40 South Street \\ Chagrin Falls, OH 44022 \\ eeharden@rci.rutgers.edu \\ Douglas L. Kruse \\ School of Management and Labor Relations \\ Rutgers University \\ 94 Rockafeller Road \\ Piscataway, NJ 08854 \\ and NBER \\ dkruse@rci.rutgers.edu
}

\author{
Joseph R. Blasi \\ Rutgers University \\ School of Management and Labor Relations \\ Levin Building \\ New Brunswick, NJ 08544 \\ and NBER \\ jrbru@hotmail.com
}




\section{INTRODUCTION}

Politicians are saying it: Michigan’s Governor, Jennifer Granholm, revealed her plan to overhaul the world's automotive center into the innovation capital of the United States, stating "the power of creativity in propelling our economy is a fundamental building block of our state's transformation” (Michigan Governor Talks, 2006). Likewise, the President of China, Hu Jintao, early in 2006, called for a transition from a manufacturing based economy to one based on innovation, recognizing that innovation is a means for China to drive their developing economy further up the value chain. Supporting this, China has announced plans to increase the percentage of GDP dedicated to R\&D spending from 1.2\% to 2.5\% by the year 2020 (Einhorn, 2006; Something New, 2006).

Organizations are enacting it: In 2005, P\&G acquires Gillette stating, "Getting the shopper to spend more comes down to innovation--the critical driver of consumer loyalty--and productivity. By doing this acquisition, we'll have more products and more innovation...” (Lafley \& Sellers, 2005). Similarly, leaders at Ford Motor Company acknowledge that their biggest challenge to succeeding in the current economy is restoring consumer's sense of confidence in the company, and say that innovation will be the means to achieve this. Underlining this importance, Ford lists "Innovation is our mission" on its home page (Elliott, Szczesny, 2006).

Academics are researching it: Recognizing the importance of innovation for the competitive advantage of organizations and larger economies, researchers are actively seeking to better understand various environmental, organizational, and individual factors which influence innovation outcomes. For example, Jaffe, Lerner, and Stern (2006) examine the role economic policies play as drivers or inhibitors of innovation activities. Other organizational research aims 
to understand the organizational factors and individual differences which impact employees' willingness to adopt organizational innovations (Klein \& Sorra, 1996).

Finally, employees are listening: Media outlets such as CNN, Business Week, and The USA Today report stories such as, “A Century of Innovation,” “The World’s Most Innovative Companies,” "Champions of Innovation,” and “The Fabric of Creativity.”

Whether it is due to globalization, expanding markets, low cost competition, or demanding customers, the need for innovation has been heard echoing from Capital Hill, to Wall Street, to the television sets of the average American. In the battle for continuous innovation, organizations play a critical role in fueling the development and production of these products, services, and processes.

Unlike the traditional view of innovation as the activity performed by the lone R\&D scientist working in isolation, today's organizations embrace the ideas and insights of employees at all levels of the organization. For example, Whirlpool credits their successful product innovations not to a couple of departments, such as engineering or marketing. Instead, they say that they have harnessed the power of a 61,000-employee workforce, providing the means for all levels and job functions to contribute and develop product, service, or processes innovations (How Whirlpool Defines, 2006).

Given the new organizational context for innovation, it is important to understand how employees at all levels of the organization can be managed to direct and align their behaviors to achieve innovative outcomes. For example, Annalee Saxenian, in her seminal work on organizational innovation, contrasts two traditional innovation hubs of America: Silicon Valley in California and Route 128 surrounding Boston. Her work indicates that two management practices, organizational structures and rewards, were critical to accounting for differences in 
innovation output. Silicon Valley spawned innovation through shared capitalism incentives and the use of teams, while innovation in the Boston corridor was stymied by bureaucratic top-down approaches to organizational structure and rewards.

Likewise, in their book In the Company of Owners, Blasi, Kruse, \& Bernstein (2003) examined in detail one innovation sector, the 100 largest corporations that built, run, and sell on the Internet. They highlight the major role that shared capitalism practices, such as employee ownership, profit sharing, and broad based stock options, in combination with a participative culture, can make in promoting organizational innovation.

Recognizing the importance of innovation for today's organizations, this study will examine the role shared capitalism and high performance work policies play as a means to achieve innovation outcomes. Additionally, we will examine a process mechanism, employee alignment, as one way in which shared capitalism and high performance work policies impact innovation outcomes.

\section{LITERATURE REVIEW}

\section{Can shared capitalism promote innovation?}

We broadly define shared capitalism as organizational incentive systems which seek to align the interests of the employee with the owner by sharing the residual return. In this way, self-interested employees will seek to increase their residual return by working to achieve organizational objectives. Shared capitalism incentives may be at the group or team level through gainsharing plans, or at the organizational level through profit sharing, employee ownership, or broad-based stock option plans. 
An extensive body of knowledge has accumulated on the impact that different forms of shared capitalism have on workplace outcomes. In general, the research indicates that shared capitalism has a positive influence on workplace outcomes. For example, there is evidence for the positive impact of shared capitalism on human resource outcomes such as turnover, loyalty, and worker effort (Freeman, Blasi, and Kruse, 2007). In addition, research supports the importance of shared capitalism for accounting- and market-based measures of performance (see Kaarsemaker, 2006, and Kruse and Blasi, 1996, for reviews). While shared capitalism plans are associated with somewhat better performance on average, there is substantial variation among individual companies, and a number of studies show no evidence of impact on workplace outcomes. One important reason for this variation appears to be differences in employment cultures, employee participation, and workplace practices that may be complements to shared capitalism in affecting workplace performance (Kruse et al., 2005).

While this cumulative body of literature on shared capitalism has greatly enhanced our understanding of the field, gaps in the research still remain. One such gap is the impact of shared capitalism on innovation outcomes. A review of the prior research identified four articles which discuss or examine the importance of shared capitalism in achieving product, service, or process innovations.

Gamble (2000) finds reduced R\&D expenditures in firms where ESOPs own larger blocks of stock and argues that this reflects management entrenchment and managerial risk aversion; in contrast, Kruse (1996) finds that R\&D expenditures are a strong predictor of the use of a profit-sharing plan, and Sesil et al. (2002) find positive effects of broad-based stock options in high technology knowledge-based industries, noting that 'for firms, in which new product development is crucial for success, such as in many knowledge-based industries, broad-based 
stock options can reduce the agency problem, resulting in greater output' (p. 276). Most recently, and supporting Sesil et al's perspective, Lerner \& Wulf (2006), using a sample of 300 publicly traded R\&D centralized firms, found that the compensation of corporate R\&D heads had dramatically shifted in the 1990's, with a heaver reliance on long-term incentives such as stock options. They find long-term incentives are positively and significantly associated with number of patent filings, patents perceived value (patent citations), and patent generality.

While research that examines the role of shared capitalism as a means to achieve innovation outcomes is in its infancy, social and behavior psychologists have actively examined the impact of individual rewards on creative behavior (Amabile, 1983; Deci \& Ryan, 1985; Eisenberger and Selbst, 1994). Thus, we briefly present empirical evidence and theoretical perspectives from the social and behavioral schools of psychology.

Social-cognitive psychologists assert that creative behavior has defining characteristics that make it distinguishable from other human behavior; in particular creative behavior is dependent on employees’ intrinsic motivation (Amabile, 1983; Deci \& Ryan, 1985). Thus, the aim for social-cognitive psychologists is to uncover the conditions which enhance employee's intrinsic motivation. According to this line of reasoning, extrinsic rewards, such as shared capitalism, will have a detrimental effect on employee's intrinsic motivation and ultimately their creative behavior by directing employee's attention towards the reward itself over the task at hand.

In contrast, behavioral psychologists argue that the effort needed to complete activities is an unpleasant sensation produced by repeated or intense performance of any behavior. Reinforcements, such as rewards, are a means by which organizations can reduce this unpleasant sensation. If an employee is rewarded for putting in a large amount of effort in an activity or 
behavior (for example through shared capitalism) it reduces the adverse impact of such behaviors and increases this behavior in the future. In effect, reinforcements work to control employee's creative behavior by decreasing the unpleasant sensations associated with the cognitive effort needed to perform creativity.

Empirically, an abundance of studies in the past 30 years have been conducted to understand if and under what conditions rewards enhance or inhibit creative behavior, with contradictory results and conclusions. Recognizing the conflicting evidence, five meta-analyses aimed to bring cohesion to the divergent results (Rummel \& Feinberg, 1988; Wiersma, 1993, Tang \& Hall, 1995; Cameron, \& Pierce, 1994; Eisenberger \& Cameron, 1996; Deci, Koesterner, \& Ryan, 1999). Of the five, the strongest support for the Cognitive Evolution Theory comes from Deci, Koestner, \& Ryan (1999) who combined 128 studies to find that all tangible and intangible rewards undermined intrinsic motivation. However, conclusions from Eisenberger \& Cameron's (1996) extensive review indicate that: (1) the detrimental effects of rewards tend to occur in highly restricted, easily avoidable conditions, (2) mechanisms of instrumental and classical conditions are basic for understanding incremental and detrimental effects of reward on task motivation, and (3) the positive effects of rewards on performance are easily attainable using procedures derived from behavioral theory.

Taken together, past theory and empirical work on creativity and rewards has failed to provide an understanding of how best, if at all, to reward employees to achieve creative behavior. Additionally, the application of this research to organizational setting is restricted. First, the majority of studies in this field have been conducted outside of organizations and relied heavily on school children, making the generalizability of these finding limited. Second, organizations are increasingly employing group/team or organizational incentives over individual incentives as 
a means to encourage cooperation and alignment (Blasi et al., 2006). Thus, studies examining individual incentives provide only a limited understanding of the full range of workplace incentives. Third, the sample sizes of studies mentioned above are generally small. For example, of the 128 studies examined in Deci, et al.’s (1999) meta-analysis the largest sample was 249, with the majority of sample sizes well under 100 . While significant effects can often be detected with these sample sizes (depending on the study design), a contribution of this study to the current literature is the large sample size obtained in an organizational setting (more than 25,000 employees in hundreds of work sites) with data on several types of workplace incentives.

\section{Can employment practices promote innovation?}

In contrast to the limited research on organizational incentives, innovation management scholars have actively researched individual human resource management policies which impact innovation outcomes, including job design (Hackman \& Oldham, 1980), selection (Woodman, Sawyer, \& Griffin, 1993; Iansiti, 1995), training (Wheatley, Anthony, \& Maddox, 1991), and performance management (Mehr \& Schaver, 1996). Mumford (2000) reviews an extensive body of literature examining specific human resource management policies that support innovation and creativity. Building on this review, the following sections summarize the management policies that are supportive of innovation and creativity in organizations.

Selection. The consistent development of innovative products, services, and processes requires a workforce with the necessary breadth and depth of technical skills (Amabile \& Gryskiewicz, 1987; Iansiti, 1995), in combination with a constant flow of new ideas and experience (Bontis, Crossan, \& Hulland, 2002; Jackson \& Schuler, 2002). Staffing practices work as a means to ensure a consistent flow of technical skills, by identifying and selecting applicants who will add new ideas and experience to the organization. Researchers have 
examined the employee characteristics supportive of innovation: divergent thinking (Guilford, 1950), technical expertise (Amabile \& Gryskiewicz, 1987; Mumford, 2000), and certain personality characteristics (Amabile, 1988; King, 1990).

Training \& Job Rotation. Maintaining employees’ current knowledge and skills, while developing new knowledge and skills, is essential to innovative performance (Cohen \& Leventhal, 1990; Mumford, 2000). Two HR policies vital to maintaining and developing employees to achieve innovative outcomes are training and development (Leonard-Barton, 1992). A firm's potential to be innovative and creative is enhanced as the new knowledge and abilities are incorporated into the organization (Jackson \& Schuler, 2002; Cohen \& Leventhal, 1990). Thus, past research has noted the importance of sabbaticals, subtracting assignments, selfstudy programs, conferences, external courses, and job rotations as important mechanisms to enhance an organization's ability to innovate (Dougherty, 1992; Mumford, 2000; Christensen \& Raynor, 2003; Amabile, 1983).

Performance Management. Performance evaluations have been both negatively and positively associated with individual innovation and creativity (Amabile, 1979; Shalley, 1995). For instance, Amabile (1979) found that individuals who expected their artistic task to be externally evaluated had significantly lower levels of creativity on the task than individuals not being externally evaluated. In contrast, Shalley (1995) conducted two studies with samples of undergraduate students; the results of both studies indicate that expecting an evaluation is not necessarily harmful to people's creativity. The variance in empirical evidence may be explained by the type of performance evaluation. Performance appraisals should not have specific performance objectives or difficult production outcomes (Mumford, 2000; Oldham, 2003). Instead, appraisals are most conducive to creativity when they consist of broadly defined goals 
and objectives that allow employees flexibility as to what the final outcome will be (Mumford, 2000).

Rewards (Recognition). As mentioned above, evidence for the impact of individual rewards on creative behavior is mixed. However, for those researchers who support the role of rewards or recognition (both intrinsic and extrinsic) for creativity, other questions remain such as the skills, behaviors, or outcomes that should be rewarded. For instance, Henderson and Cockburn (1994) in their investigation of the pharmaceutical industry suggest firms that promote researchers according to their standing in the scientific community enjoyed higher productivity levels. Additionally, rewards should not be withheld from employees who step out of established roles or fail to achieve desired outcomes. Instead, a better approach is to reward employees for their effort or progress toward an innovation/creative goal or objective (Mumford, 2000). Finally, Dougherty (1992), after extensive field research on product development, suggests that rewards should be provided for the development of expertise, skills, and competencies. Thus, beyond compensation, other forms or rewards and recognition can be used to enhance creative behavior.

Employee involvement. Empowering employees and utilizing teams are two mechanisms through which employee participation can enhance organizational innovation (Mumford, 2000). Christensen and Raynor (2001) argue that successful product innovation requires big decisions to be driven down to the lowest level. They reason that decisions about products, services, and processes innovations should be made on the spot, instead of waiting for a response from further up in the organization. Additionally, Jelinek \& Schoonhoven (1990) note employee involvement helps employees to see their part in the innovation process while creating a shared responsibility in the outcome. Supporting this, Leonard-Barton (1994), in her study of innovative projects 
groups, found that empowerment is most important for innovative capabilities. Those project teams who were empowered felt 'exhilarated by the challenges they had created' (p. 117).

Teamwork. The use of team-based work is a popular mechanism for enhancing innovation. Innovations involve different types of tasks and processes, and thus are rarely the creation of one individual or a single department. Team-based work has been argued to increase the speed of product innovation (Hayes, Wheelwright, \& Clark, 1988), the number of innovations (Dougherty, 1992), and the value of the innovation (Ven de Ven, 1986). For example, Clark and Fujimoto (1991) conducted a qualitative study where they found that the use of cross-functional teams is central to the product development process. Additionally, effective product development was not housed in solely specialized R\&D activities; instead the most effective product development came from creating linkages between various departments within the organization. Thus, the use of teams enhances product innovation through the diversity of knowledge (Cohen \& Levinthal, 1990).

Systems Perspective. While the above policies appear to be valuable for innovation, recent work recognizes the importance of examining HRM policies as a bundle or system of policies as opposed to individual policies in isolation (MacDuffie, 1995; Huselid, 1995; Ichniowski et al., 1996; Blasi and Kruse 2006). A central tenet of the systems approach is that organizations should create a high degree of internal consistency among their HRM policies (Barid \& Meshoulam, 1988). Systems of HRM policies which are designed to utilize the knowledge and skills of the workforce have been labeled as "high performance," "high involvement,” "high commitment,” “HR sophistication,” and “HR investment.”

Interestingly, there is wide disagreement on what policies constitute "high performance." A review by Lepak, Liao, Chung, and Harden (2006) highlights the disparate and at times 
conflicting policies making up high performance systems. While disagreement remains over the policies represented in a "high performance" work system, it is generally agreed that a high performance work system (HPWS) can impact various organizational outcomes. Collectively, 20 years of cumulative research has found HPWS are strongly associated with outcomes including HRM outcomes (i.e., turnover, absenteeism, job satisfaction), organizational outcomes (i.e., productivity, quality, service), financial accounting outcomes (i.e., ROA, profitability), and capital market outcomes (i.e., stock price, growth, returns) (Coombs, 2006; Becker \& Huselid, 2006). ${ }^{1}$

As noted above, employee knowledge and skills are critical to achieving innovation outcomes. Thus, it is surprising that the systems approach has had limited application to innovation outcomes. Studies of high performance workplace bundles have so far tended to focus on operational or financial performance without measures of innovation. Given the limited empirical evidence, our study seeks to fill this gap by examining the impact of HPWS on innovation outcomes.

Taken together, the limited empirical work examining the effects of shared capitalism and HPWS on innovation outcomes represents a gap in the literature that needs to be addressed. Our interest is to examine the relationship between shared capitalism, HPWS, and innovative outcomes, in addition to the intervening mechanisms that uncover how these relationships occur. The following theory and hypotheses development provides the rational for why we expect these relationships to occur.

1 Despite these positive performance outcomes, bundles of high performance workplace policies appear to have very low incidence among firms (Blasi and Kruse 2006). See Ichniowski et al. (1995) regarding the barriers to adoption of high performance policies. 


\section{THEORY \& HYPOTHESES}

Laffont and Martimort (2003) describe the principal-agent problem as a fundamental one for the firm: "Indeed, for various reasons the owner of the firm must delegate several tasks to the members of the firm. This necessity raises the problem of managing information flows within the firm...The starting point of incentive theory corresponds to the problem of delegating a task to an agent with private information” (2003: 2-3). For the purposes of this article, one can think of the problem of innovation as how to get the members of the firm interested in working alone or together to use their information to achieve innovation that will profit the owner of the firm.

They cite the early work of both Chester Barnard and Charles Babbage in defining the relevance of shared capitalism for the agency problem. For example, Babbage wrote:

The general principles on which the proposed system is founded, are: 1. That a considerable part of the wages received by each person should depend on the profits made by the establishment; and 2. That every person (our emphasis) connected with it should derive more advantage from applying any improvement he might discover than he could by any other course." (Laffont and Martimort 2003: 11 quoting Babbage 1989:Vol 8: 177)

One can readily see that Babbage is specifically addressing both shared capitalism and innovation (“any improvement”). Barnard's views were more explicit and more extreme when he wrote:

An essential element of organizations is the willingness of persons to contribute their individual efforts to the cooperative system... Inadequate incentives mean dissolution, or changes in organizational purpose, or failure to cooperate. Hence in all sorts of organizations the affording of adequate incentives becomes the most definitely emphasized task in their existence. It is probably in this aspect of executive work that failure is most pronounced. (Laffont and Martimort 2003: 12 quoting Barnard 1938:139)

The research on the effect of individual incentives on innovation is mixed, as noted above, while the research on teamwork generally shows it to be positively related to innovation efforts. One of the purposes of shared capitalism plans is to enhance teamwork by creating greater 
cooperation and information sharing among co-workers, and between workers and supervisors/managers. Based on this our first hypothesis is:

Hypothesis One: Shared capitalism incentives are associated with a workplace culture that is supportive of innovation efforts.

Hypothesis Two: Shared capitalism incentives are associated with a greater willingness of employees to report innovative ideas.

In line with our interest in exploring the impact of employment culture, specifically high performance work systems, on innovation, past theorists have given some thought to the role of organization design as a complement to incentives.

For example, Barnard virtually defined the high performance work system when he wrote about what Laffont and Mortimort call “nonmonetary incentives” as including: “ personal nonmaterial opportunities; ideal benefactions; . . associational attractiveness; adaptation of conditions to habitual methods and attitudes; opportunity of enlarged participation; [and] the condition of communion.” Barnard stressed that what we think of as financial incentives had to be "reinforced by other incentives," specifically referring to these organizational components (Laffont and Martimort 2003: 12 quoting Barnard 1938:142).

In a modern economy where workers are often not manipulating physical objects, much of work itself is inside the mind of the worker and is about collecting, communicating, sharing, manipulating, and combining information in novel and innovative ways. Physical monitoring by supervisors as a solution to the agency problem is very hard in these environments. Many of the features of high performance work systems that theorists like Huselid have defined are essential to innovations are based on information. A number of these high performance policies can create conditions that favor innovation: good wages and benefits can produce high commitment 
and loyalty; selective recruitment can get the most informed and curious persons into an organization; training can upgrade their informational and cooperative skills; teamwork and job rotation can break down "rigid silos" between them; and employee involvement can bring them closer to the information that both customers and management possess. This is not dissimilar from the classic agency theory notion of the "revelation principle" in which societies have a problem in how to get "informed agents (to) reveal private information to a planner who recommends actions” (Laffont and Martimort 2003: 26-7). One can conceive of a high performance work system as a workplace mechanism to make the revelation principle work. Based on the theory and research linking high performance work systems to organizational performance, we expect that an HPWS will also contribute to an innovative culture and activity, and will complement shared capitalism plans. Our next four hypotheses are: Hypothesis Three: High performance work systems are associated with a workplace culture that is supportive of innovation efforts.

Hypothesis Four: High performance work systems are associated with a greater willingness of employees to report innovative ideas

Hypothesis Five: Shared capitalism plans have a positive interaction with high performance work systems in predicting a workplace culture that is supportive of innovation efforts.

Hypothesis Six: Shared capitalism plans have a positive interaction with high performance work systems in predicting willingness of employees to report innovative ideas.

Finally, we expect that if the above effects exist, they operate in part through greater alignment of employees with the company’s strategy. Our final two hypotheses are: 
Hypothesis Seven: Individual alignment with company strategy mediates the relationship of shared capitalism and high performance work systems to a workplace culture that is supportive of innovation efforts.

Hypothesis Eight: Individual alignment with company strategy mediates the relationship of shared capitalism and high performance work systems to the willingness of employees to report innovative ideas.

\section{DATA AND METHODS}

\section{Data Set}

The NBER Shared Capitalism Research Project developed a dataset to better understand how shared capitalism impact innovation outcomes. The data set includes employee surveys from a single company with a broad profit sharing program and opportunities for employee ownership. This company agreed to participate in a larger shared capitalism study that included 14 organizations, described in more detail in the companion paper by Kruse, Blasi, and Park (2006). Unique to this company, the survey asked a series of questions about organizational innovation. The survey was administered in 2006 via paper and web-based administration. A total of 27,825 usable surveys were returned for a response rate of $67.3 \%$. Missing data for one or more of the variables reduced the sample to 25,014 respondents who had complete data for all of the variables.

\section{Measures}

Human Resource Management. The 5-P model (Schuler, 1992) identifies the various ways in which HRM activities can be examined, as philosophies, policies, programs, practices, or processes. This study will examine HRM policies and practices. 
Policies, as defined here, are the broadly defined HRM activities. For example, performance-based pay is a broadly defined measure of a HRM activity, but it can be implemented through a number of different practices. By assessing HRM policies, a researcher is able to cast a wide net in understanding the HRM activities within the organization. However, HRM policies limit the detailed information on what specific practices make up a policy.

Alternatively, HRM practices are the specific HRM activities which are employed to implement a HRM policy. For example, under the policy of pay-for-performance there are different HRM practices that can be employed to achieve the pay-for-performance policy. Assessing specific HRM practices provides a level of detail missed by HRM policies. In this study, the primary interest is the impact of shared capitalism, and its various forms, as a means to achieve innovation outcomes. Thus, we examine the individual shared capitalism practices and a combined shared capitalism index that can be utilized to achieve innovation outcomes, discussed in more detail below.

We examine two systems of HRM policies. First, we analyze a high performance work system (HPWS) which includes employee participation, training, job rotation or cross-training, selection, job security, and information sharing. The majority of questions (listed in Appendix A) ask the respondent to report if s/he is covered by this policy. Second, a high performance work system measure was included which asked employees their perceptions of the effectiveness of each high performance policy for their work area or team. This measure thus localizes and focuses the estimation of the high performance practices within the group of workers immediately surrounding the respondent. This is notable, since most HRM scholars do not bring high performance work literature down to the lowest level of the organization (notable exceptions include Allen, Shore, \& Griffith, 2003 and Zacharatos, Barling, \& Iverson, 2005). In 
particular, this index measures team effectiveness in the following areas: selection, performance goals, training, sharing information, meeting with customers, and rewards. This human resource policy index is referred to as high performance work system - team (HPWST).

Shared Capitalism. As noted above, shared capitalism appears in a variety of forms. This study examines profit/gainsharing, employee ownership, and stock options. Profit sharing and gainsharing are combined here because this firm has one program combining elements of each: bonus payments are based both on company-wide return on net assets, and on division performance. In addition, we examine the effects of individual incentives. For each incentive plan, the presence of the incentive (yes/no) and the extensiveness of the incentive (as a percent of total fixed annual pay) are examined. Additionally, a thermometer-style index of shared capitalism was constructed. The index, described in Appendix B, reflects both whether workers have different shared capitalism programs and whether these programs represent a high percentage of the worker's fixed annual pay.

Workplace Outcomes. After consulting with the research literature, two comprehensive measures of innovation were designed. The first is focused on measuring aspects of a firm's culture for innovation. According to organizational theory on creativity, employees' innovative behavior can be influenced by the environment or culture an employee encounters (Amabile, 1988). Thus, an important outcome to understand is a culture that supports innovative behavior. An extensive review of the literature on cultures that support innovation revealed consistent characteristics across cultures that support innovation. For example, companies can promote innovation by fostering an environment that encourages employees to voice ideas or suggestions, provides the resources to further develop ideas, and recognizes the efforts of employees who do try to innovate (Scott \& Bruce, 1994). Given the past literature, our study examines the 
characteristics listed above. The specific items for the culture of innovation scale are listed in Appendix A.

The second measure focuses on individual employee's willingness to marshal their innovative ideas and do something about it. Innovative behaviour is characterized by a multistage process, with different activities or behaviours necessary at each stage (Scott \& Bruce, 1994). In this study, we examine an employee's ability and willingness to generate ideas, as opposed to their actual innovative behavior. Specific items developed to assess employee willingness to innovate are listed in Appendix A.

Finally, we examine the extent to which employees are aligned with the goals and objectives of the organization (Huselid, Becker, \& Beatty, 2005). Aligning employees with organizational goals and objectives has become an increasingly important task; especially in organizations where employees’ knowledge and skills play a critical role in achieving strategic objectives, such as innovation. It is through alignment that employees are aware of how they can contribute to achieving organizational objectives. Much of the work arguing for the importance of aligning employees behind shared goals and objectives has been at a conceptual level (Wright \& McMahan, 1992; Boswell \& Wright, 2002). Thus, this research contributes to the current literature by going beyond the importance of aligning HRM policies to organizational strategy (Huselid, 1995). It looks deeper into the organization for how employees, the individuals who implement strategic objectives, recognize and agree with them. Our interest is to examine if and to what extent shared capitalism and high performance work policies are effective means to align a workforce behind organizational objectives. Our measure combines four items representing 
employee understanding and agreement with the company strategy, and employee views of whether the company provides the resources and culture necessary to implement that strategy. ${ }^{2}$

\section{EMPIRICAL RESULTS}

\section{Culture for Innovation}

Table 1 summarizes the empirical results on the relationship between shared capitalism, high performance work policies and employees’ perception of a culture for innovation.

Shared Capitalism. In Models 1, 3, and 5 we examine the impact of the shared capitalism index on employees' perception of a culture for innovation. The results reveal that the shared capitalism index is positively related to employees’ perception of a culture for innovation (Model 1). The shared capitalism index remains positively related when HPWST is added to the equation (Model 5), but not when HPWS is added (Model 3), so there is only partial support for hypothesis 1.

When the shared capitalism practices are broken out to examine their individual impact on employees' perceptions of a culture for innovation (Models 2, 4, and 6), two shared capitalism practices are consistently related to employees’ perceptions of a culture for innovation: the percentage of base pay going to profit/gainsharing, and owning company stock. These results stay strong when adding in either the HPWS or HPWST measure, supporting hypothesis 1 for these two pay practices.

High Performance Work Policies. A very consistent result in Models 3-6 is the strong positive association between human resource management policies and employees' perceptions of a culture for innovation. An examination of adjusted R-squared with and without the human

\footnotetext{
${ }^{2}$ We thank Mark Huselid for insightful comments and suggestions on developing the employee alignment scale.
} 
resource practices indicates that these practices greatly increase our ability to account for what might create a culture for innovation. These results support hypothesis 3 and underline the important role high performance policies have in creating and supporting a culture for innovation where employees are encouraged to innovate, are rewarded for this, and are provided the resources to do so.

\section{Innovative Ideas}

Table 2 summaries the empirical results on the relationship between shared capitalism, high performance work policies, and employees’ willingness and ability to innovate.

Shared Capitalism. In Models 1, 3, and 5 we report the impact of the shared capitalism index on employees' willingness and ability to contribute innovative ideas to the organization. The results, consistent with those reported for a culture for innovation, find that those employees who reported higher levels of shared capitalism also reported higher willingness and ability to contribute innovative ideas to the organization. These results remained significant after including measures of high performance work policies, supporting hypothesis 2 .

When the shared capitalism policies are broken out in columns 2, 4, and 6, employee ownership is again a significant positive predictor of employees' willingness and ability to contribute innovative ideas to the organization. Unlike the results for culture of innovation, however, profit/gainsharing as a percent of pay is not a significant predictor, and in fact profit/gainsharing eligibility is a negative predictor in two of the models. These latter results contrast strikingly with the positive results for employee ownership, suggesting that profit sharing may focus workers toward short-term outcomes and away from activities with a longterm payoff, while employee ownership helps promote behavior like innovative activity that will 
have a longer-term payoff. ${ }^{3}$ This is because profit sharing in the organization under study specifically rewards employees for productivity and operational achievements (such as on-time customer delivery) of delivering current goods and services which the organization sees as part of its existing repertoire of offerings. Profit sharing is not, however, tied to ideas or prototypes for future goods and services.

High Performance Work Policies. The impact of high performance work policies on employees' willingness and ability to contribute innovative ideas to the organization is reported in Models 3-6. The results, across all models, reveal a consistent and significant positive relationship between both high performance work policy indexes and employees' willingness and ability to contribute innovative ideas to the organization. Given these results, support was provided for hypothesis 4 . Taken together, these results can be interpreted to signify that the use of high performance work policies is one way to increase employees' willingness and ability to contribute innovative ideas to an organization.

An interesting note is that in comparison to the HPWS impact on a culture for innovation, it appears that the HPWS impact is not as substantial for willingness and ability to contribute innovative ideas. We speculate that an employee's ability to contribute innovative ideas may be accounted for by individual differences not captured in this study. For example, divergent thinking (Guilford, 1950), openness to new experience (Feist, 1998), and internal locus of control (Woodman \& Schoenfeldt, 1989) have all been related to highly innovative or creative individuals.

3 This interpretation was supported by several company representatives at the conference where this paper was initially presented. One person noted that ROI, which stands for return on investment, was sometimes referred to by employees as "repression of innovation" because a focus on short-term profitability discourages investments in innovative activities that have a longer-term payoff. 


\section{Complementarities between Human Resource Policies and Shared Capitalism}

An important proposition of the systems perspective is that organizational outcomes will be enhanced to the extent that a firm's human resource management activities fit with and complement one another (Baird and Meshoulam, 1988). The underlying rationale is that the more strongly human resources fit together, the more consistent are the signals communicated to employees regarding the behaviors that are valued by the organization (Becker \& Huselid, 1998). While fit can be tested using various statistical techniques (Venkatraman, 1989), we employ a fit-as-moderation hypothesis, testing whether the impacts of shared capitalism on innovation outcomes are dependent on the level of high performance work policies. Stated differently, we expect that the impact of shared capitalism on employees’ perceptions of a culture for innovation vary across levels of high performance work policies. To examine this, an interaction term was included in Table 3 (Models 1 and 2).

The results indicate that shared capitalism does interact positively and significantly with both HPWS and HPWST and provides support for hypothesis 5. The fit between shared capitalism and HPWST was positively related to employees’ perception of a culture for innovation. Likewise, the interaction between shared capitalism and HPWS was positive and marginally significant. To further help with interpretation, the interaction results are portrayed in Figure 1 (using Table 3, Model 2). As seen there, shared capitalism has the most positive relationship to innovation culture when HPWST is at high levels, with a mild positive relationship when HPWST is at average levels. The relationship is negative when HPWST are at low levels, indicating that employees may perceive the innovation culture poorly when they are given the incentives, but not the tools, to make a difference--in this case the shared capitalism may be perceived as primarily a shifting of financial risk to employees. 
There are very different results, however. in predicting willingness or ability to innovate. As reported in Table 3 (Models 3 and 4) we find that while the base effects are positive and significant, the interaction between the shared capitalism index and high performance work practices is negative and significant for both HPWS and HPWST. These results indicate that when employees are covered by high performance work practices, the impact of shared capitalism policies on their willingness and ability to innovate for the organization is reduced. Put another way, the positive base effects and negative interaction indicates that these two constructs may substitute for each other: the base effect shows that shared capitalism has a positive effect on innovative activity for those who are not covered by HPWS, but shared capitalism has a much smaller or neutral effect for those who are covered by HPWS. An HPWS appears to provide a strong effect on its own, perhaps making unnecessary the addition of shared capitalism incentives.

To further help with interpretation, the interaction results are portrayed in Figure 2 (using Table 3, Model 4). Shared capitalism has a strong positive association with innovative ideas for workers with low values on HPWST, and only a mild positive association when HPWST is at high levels. These illustrate the point made above: high performance work policies and shared capitalist incentives may act somewhat as substitutes here, with shared capitalism providing the strongest incentives for contributing ideas among those who have not been encouraged to contribute ideas through high performance work policies.

\footnotetext{
Alignment

Table 4 summaries the empirical results on the relationship between shared capitalism, high performance work policies, and organizational alignment.
} 
Shared Capitalism. The results listed in Model 1, 3, and 4 indicate that shared capitalism may play a significant and positive role in aligning employees behind the goals and objectives of the organization. Even in the presence of high performance work policies, shared capitalism continues to play a significant and positive role in employee alignment. There are different results when interacting shared capitalism with the two HPWS measures: the base effect of shared capitalism stays strong and the interaction is insignificant in Model 3, while the opposite is true in Model 6. It is therefore unclear whether shared capitalism operates on its own or only in combination with HPWS in affecting alignment. The results of specific shared capitalism practices on employee alignment are also not consistent between the models controlling for different measures of HPWS. Stock option holding and profit/gainsharing as a percent of pay are predictors when controlling for HPWS, while profit/gainsharing eligibility and employee ownership as a percent of pay are predictors when controlling for HPWST. It is noteworthy that individual bonus eligibility (but not the bonus size) is a strong predictor of alignment, possibly reflecting greater bonus eligibility among high-level managers (not fully captured in the management level controls).

High Performance Work Policies. Consistent with the results for a culture for innovation and innovative ideas, high performance work policies continue to have a strong impact in Models 1 to 6 of Table 4. An interesting finding is the relative impact of the HPWS vs. the HPWST on alignment. The adjusted R-square for the models with HPWST accounts for a greater amount of variance in the alignment of employees. This result could indicate that the greater impact on employee alignment is not when employees experience high performance policies (HPWS), but when they perceive these practices as effective (HPWST) in the context of their 
immediate local work group or team. This finding suggests that the level of measurement of high performance work practices is important.

Complementarities between Human Resource Policies and Shared Capitalism. Once again, using interaction terms we examined the impact of the complementary relationship between human resource management policies and shared capitalism on employee alignment. The only significant result is reported in Model 6. Here shared capitalism interacts with HPWST and results in a positive effect on employee alignment. This result confirms the importance of ensuring that human resource policies and shared capitalism complement each other in order to achieve maximum benefits. Again, it is interesting to note that the interaction with shared capitalism was only significant with HPWST, which indicates the importance of perceived policy effectiveness in work groups over the mere presence of policies. It appears that such practices need not only to be bundled together but need to be bundled together in a way that is seen as effective within a local work group.

\section{Mediating Role of Alignment}

Across the results, a consistent finding is that HRM policies and shared capitalism are related to employees' perception of a culture for innovation and employees' willingness and ability to contribute innovative ideas. However, it is not clear how HRM policies and shared capitalism impact these outcomes (Becker \& Gerhart, 1996; Ostroff \& Bowen, 2000). For instance, management scholars have argued that HRM policies impact organizational outcomes through organizational culture (Ostroff \& Bowen, 2000), organizational commitment (Allen, Shore, \& Griffeth, 2003), and employee skills, motivation, and opportunities (Lepak, et al., 2006). 
While the intervening mechanisms listed above are plausible, our interest is the impact HRM policies have in creating employee alignment. To test for mediation, three models are run to test four conditions (Baron and Kenny, 1986). First, the independent variable (HRM policies or shared capitalism index) must significantly impact innovation outcomes. Second, the independent variable must significantly impact the mediator (alignment). Third, with the independent variable in the equation, alignment must impact innovation outcomes. The fourth necessary condition is a decrease in the coefficient between the independent variable and innovation outcomes as alignment is added. Using this technique it is possible to assess if the coefficient between the independent variable and the outcomes decreased with alignment in the equation. The extent of reduction in the coefficient reveals how much of the relationship between the independent variable and dependent is indirectly working through the mediator (alignment). Finally, Sobel's test is employed to ensure that the drop in the coefficient is significantly different from zero (Sobel, 1982). Tables 5 and 6 reports the results of the test of mediation.

Shared Capitalism. The results in Tables 5 and 6 reveal that alignment does partially mediate the relationship between shared capitalism and employee's perception of a culture for innovation. This is indicated by the reduction in the shared capitalism coefficient from Model 4 to Model 6, and a significant value for Sobel's test, in both tables. Combined, these results suggest that one way in which shared capitalism impacts innovation outcomes is by aligning the workforce behind the goals and strategic objectives of the organization. However, the shared capitalism coefficient was not reduced to zero for either outcome, implying other mechanisms are working between shared capitalism and innovation outcomes. These findings indicate that the overall corporate culture that binds employees together (understanding and agreeing with common goals, having the tools and involvement to advance those goals, and believing the 
culture is right to achieve these goals) does play a key role in determining how shared capitalism incentives relate to innovation but that there still exists an independent incentive effect from shared capitalism. This is very similar to Barnard's view above concerning the need for a package of monetary and non-monetary incentives. The sense of common enterprise that results from shared capitalism appears to impact the agency problem by reinforcing a common culture among the members of the firm, yet the pure incentive effect of shared rewards themselves also appears to focus the individual worker (similar to the findings in Freeman, Kruse, and Blasi, 2007).

High Performance Work Policies. Also reported in Tables 5 and 6 is the mediating role of alignment with high performance work policies. Specifically, the analysis reveals that alignment partially mediates the relationship that HPWS (Models 1-3) and HPWST (Models4-6) have with employees' perception of a culture for innovation. A similar result is obtained in predicting and employees’ willingness and ability to contribute innovative ideas (Table 6). These results indicate that part of the effect of high performance work policies on innovation outcomes is through aligning the workforce behind shared goals and objectives. However, since the high performance work system coefficients are not reduced to zero, high performance work policies also impact the innovation outcomes through additional means.

\section{CONCLUSION}

The principal findings of this paper are that shared capitalism and high performance work policies affect innovation outcomes through direct effects, interactions, and indirect effects. The results of this study contribute to the current literature on shared capitalism and human resource management literature in a number of ways. First, empirical research on the importance of 
rewards and compensation practices as a means to achieve innovation outcomes is limited. This study adds to and extends the literature by examining multiple forms of shared capitalism and their impact on innovation outcomes. We demonstrate these effects in a population of adult workers in a large sample of respondents in hundreds of work sites, which provides several advantages in relation to past research. Additionally, we were able to identify a possible mediating mechanism between shared capitalism and innovation outcomes. Second, taking a systems perspective, we investigate the impact of two systems of high performance work policies on innovation outcomes. While innovation management scholars have examined the impact of individual human resource management practices on creativity or innovation, a systems approach has, to our knowledge, never been published (Harden, 2006).

Organizations seeking to develop a culture of innovation could look to this research as an answer for how this occurs. Specifically, our results reveal that a culture for innovation can be developed and supported through the use of shared capitalism and high performance work practices. We found moderate support for the importance of pairing shared capitalism and high performance work practices together to achieve the greatest impact on a culture for innovation. Additionally, shared capitalism and high performance work practices work in part by aligning employees around the goals and objectives of the organization.

As organizations increasingly depend on all employees to contribute innovative ideas to the organization, this research aims to address the role that shared capitalism and high performance work policies play to achieve these ends. The results of this study indicate that a means to promote employee willingness and ability to contribute innovation ideas is the use of high performance work policies and shared capitalism, both of which had a strong positive relationship with this outcome. However, an interesting finding of this study is that the impact of 
shared capitalism on innovative ideas varies by the level of high performance work policies the employee experiences in his or her work group. And finally, the indirect effect of high performance work practices and shared capitalism on innovative ideas indicates that an aligned employee is more willing and able to contribute innovative ideas to the organization. Shared capitalism and high performance work practices are one way to align an employee behind the goals and objectives of the organization. This last point introduces a conundrum for the manager looking for a practical application of the findings. A manager can implement shared capitalism practices and high performance work practices, but how does a manager implement alignment? Does the manager just presume that whatever alignment appears is "produced" by shared capitalist and high performance work practices? The answer is no. This would be tantamount to flying blind on what will probably be a critical measure of future innovation success for an organization. The best response is to regularly measure the workforce's alignment and use focus groups and other methods to assess why alignment may be low and reconceive the practices and the overall corporate culture accordingly (Huselid, Becker, \& Beatty, 2005).

To the extent that innovation can be conceived as a principal-agent problem, we have demonstrated that a system of shared incentives and a shared high performance employment culture at the lowest levels of organizations is important to create both an innovative environment that is fertile ground for innovative ideas, and the willingness to work on innovative ideas. Taken together, these findings indicate that the overall corporate culture that binds employees together does play a key role in determining how shared capitalism incentives relate to innovation, but there still exists an independent incentive effect from shared capitalism. The sense of common enterprise that results from shared capitalism appears to impact the agency 
problem by reinforcing a common culture among the members of the firm, yet the pure incentive effect of shared rewards themselves also appears to focus the individual worker.

In summary these findings confirm several of the main themes of agency theory: that the principal-agent problem can be addressed by incentives, and that agency conflicts respond to a cooperative culture between workers which encourages mutual monitoring and opportunities to share information. The results of this study make two unique and nuanced contributions to this perspective: first, that it is the combination of shared incentives, cooperative culture, and mutual monitoring that works best, and second, that high performance workplace systems help resolve agency problems when employees work in teams at the lowest level of the organization that are rich with rigorous selection, training, information sharing, clear goals, and fair rewards. 


\section{REFERENCES}

Allen, D. G., Shore, L.M., \& Griffeth, R.W. 2003. "The role of perceived organizational support and supportive human resource practices in the turnover process," Journal of Management, 29: 99-118.

Amabile, T. M. 1979. “Effects of external evaluation on artistic creativity,” Journal of Personality and Social Psychology, 37: 221-233.

Amabile, T. M. 1983. The social psychology of creativity. New York: Springer-Verlag New York Incorporated.

Amabile, T. M. 1988. "Poetry in a Nonpoetic Society,” Contemporary Psychology, 33: 65-66.

Amabile, T., \& Gryskiewicz, N. D. 1989. “The creative environment scales: Work environment inventory,” Creativity Research Journal, 2: 231-253.

Baird, L., \& Meshoulam, I. 1988. "Managing two fits of strategic human resource management," Academy of Management Review, 13: 116-128.

Barnard, C. I. 1938. The Functions of the Executive. Cambridge, MA: Harvard University Press.

Baron, R. M., \& Kenny, D. A. 1986. „The moderator-mediator variable distinction in social psychological research: Conceptual, strategic and statistical considerations,” Journal of Personality and Social Psychology, 51: 1173-1182.

Bartholomew, D.J., Steele, F., Galbraith, J.I., \& Moustaki, I. 2002. The Analysis and Interpretation of Multivariate Data for Social Scientists. Boca Raton, FL: Chapman and Hall/CRC.

Bartholomew, D. 1996. The Statistical Approach to Social Measurement. London: Academic Press.

Becker, B. E., \& Huselid, M.A. (In press). "Strategic Human Resource Management: Where Do We Go from Here?” Journal of Management.

Becker, B. E., \& Huselid, M.A. 1998. "High performance work systems and firm performance: A synthesis of research and managerial implications.” In G. Ferris (Ed.), Research in Personnel and Human Resource Management, Vol. 16: 53-101. Greenwich, CT: JAI Press.

Blasi, J., Kruse, D., \& Freeman, R. 2006. "The Changing Nature of Worker Ownership, Stock Options, and Profit Sharing in Corporate America.” In Edward Lawler and James O'Toole, Eds., The New American Workplace. Palgrave Macmillan Publishers.

Blasi, J. and D. Kruse. 2006. “High Performance Work Practices at Century’s End,” Industrial Relations 45(4): 547-578. 
Bontis, N., Crossan, M.M., \& Hulland, J. 2002. "Managing an organizational learning system by aligning stocks and flows,” Journal of Management Studies, 39: 437-469.

Boswell, W. ,\& Wright, P. 2002. "Desegregating HRM: A Review and Syntheses of Micro and Macro Human Resource Management Research," Journal of Management, 28, 247-276.

Cameron, J., \& Pierce, W.D. 1994. "Reinforcement, reward and intrinsic motivation: A metaanalysis,” Review of Educational Research, 64: 363-423.

Christensen, C. M., \& Raynor, M.L. 2003. The innovators solution: Creating and sustaining successful growth. Boston: Harvard Business School Press.

Clark, K. B., \& Fujimoto, T. 1991. Product Development Performance: Strategy, Organization And Management In The World Auto Industry. Boston: Harvard Business School.

Cohen, J., Cohen, P., West, S., \& Aiken, L. 2003. Applied multiple regression/correlation analysis for the behavioral sciences (3rd ed.). Hillsdale, NJ: Lawrence Erlbaum Associates.

Cohen, W. M., \& Levinthal, D.A. 1990. “Absorptive capability: A new perspective on learning and innovation,” Administration Science Quarterly, 35: 128-152.

Combs, J., Liu, Y., Hall, A.A., \& Ketchen, D. 2006. “How much do high-performance work practices matter? A meta-analysis of their effects on organizational performance,” Personnel Psychology, 59: 501-528.

Deci, E. L., \& Ryan, R. M. 1985. Intrinsic motivation and self-determination in human behavior. New York: Plenum.

Deci, E. L., Koestner, R., \& Ryan, R. M. 1999. “A meta-analytic review of experiments examining the effects of extrinsic rewards on intrinsic motivation,” Psychological Bulletin, 125: 627-668.

Dougherty, D. 1992. "A practice-centered model of organizational renewal through product innovation,” Strategic Management Journal, 13: 77-92.

Elliott, D., \& Szczesney, J. 2006. “My goal is to fight Toyota,” Time, January 30, 167(5): 47.

Einhorn, B. 2006, April 3. “Blinding science: China’s race to innovate,” Business Week Online.

Eisenberger, R., \& Cameron, J. 1996. “Detrimental effects of reward: Reality of myth?” American Psychologist, 51: 1153-1166.

Eisenberger, R., \& Selbst, M. 1994. “Does reward increase or decrease creativity?” Journal of Personality and Social Psychology, 66: 1116-1127. 
Feist, G. J. 1988. "A meta-analysis of personality in scientific and artistic creativity,” Personality and Social Psychology Review, 2: 290-309.

Freeman, Richard, Douglas Kruse and Joseph Blasi. 2007. "Worker Responses to Shirking." Presented at NBER/Russell Sage Foundation conference, New York, NY, October 2006.

Guilford, J. P. 1950. “Creativity,” American Psychologist, 5: 444-454.

Hackman, J. R., \& Oldham, G.R. 1980. Work redesign. Reading, MA: Addison-Wesley.

Harden, E.E. 2006. High performance work practices and firm performance: Assessing the mediating role of innovative capabilities and the moderating role of strategy. Master's Thesis, Rutgers University.

Hayes, R. H., Wheelwright, S.C., \& Clark, K.B. 1988. Dynamic Manufacturing. New York: Free Press.

Henderson, R., \& Cockburn, I. 1994. "Measuring competence? Exploring firm effects in pharmaceutical research,” Strategic Management Journal, 15: 63-84.

How Whirlpool Defines Innovation. 2006. Business Week, March 6.

Huselid, M. 1995. “The impact of human resource management practices on the turnover, productivity, and corporate financial performance,” Academy of Management Journal, 38: 635-672.

Huselid, M. A., Becker, B.E., \& Beatty, R.W. 2005. The workforce scorecard: Managing human capital to execute strategy. Boston: Harvard Business School.

Iansiti, M. 1995. "Shooting the Rapids: Managing Product Development in Turbulent Environments,” California Management Review, 38: 37-58.

Ichniowski, C., \& Shaw, K. 1995. “Old Dogs and New Tricks: Determinants of the Adoption of Productivity-Enhancing Work Practices,” Brookings Papers on Economic Activity, Microeconomics 1995, pp. 1-55.

Ichniowski, Casey, Thomas Kochan, David Levine, Craig Olson, and George Strauss. 1996. "What Works at Work: Overview and Assessment," Industrial Relations, 35(3) 299-333.

Jackson, S. E., \& Schuler, R. S. 2002. "Managing individual performance: An individual perspective.” In S. Sonnentag (Ed.), Psychological management of individual performance, pp. 371-390. New York: John Wiley and Sons.

Jaffe, A., Lerner, J., \& Stern, S. 2006. Innovation Policy and the Economy, Volume 6. Cambridge, MA: The MIT Press. 
Jelinek, M., \& Schoonhoven, C.B. 1990. Innovation Marathon: Lessons from high technology firms. Oxford: Basil Blackwell.

Jintao, H. 2006. “Something new,” Economist, August 5, 380(8489): 38-39.

Kaarsemaker, E.C.A. 2006. Employee ownership and human resource management: a theoretical and empirical treatise with a digression on the Dutch context. Doctoral Dissertation, Radboud University Nijmegen, Nijmegen.

King, N. 1990. “Innovation at work: The research literature.” In M. A. W. J. L. Farr (Ed.), Innovation and Creativity at Work: 15-59. New York: Wiley.

Kruse, D. 1996. “Why Do Firms Adopt Profit Sharing and Employee Ownership Plans?” British Journal of Industrial Relations, 34, 515-38.

-----, \& Blasi, J. 1997. “Employee Ownership, Employee Attitudes, and Firm Performance: A Review of the Evidence.” In Daniel J.B. Mitchell, David Lewin, and Mahmood Zaidi, eds., Handbook of Human Resource Management. Greenwich, CN: JAI Press, pp. 113151.

-----, Joseph Blasi, and Rhokeun Park. 2008. "Shared Capitalism in the U.S. Economy: Prevalence, Characteristics, and Employee Views of Financial Participation in Enterprises.” Presented at NBER/Russell Sage Foundation conference, New York, NY, October 2006.

Kruse, D., Freeman, R., Blasi, J., Buchele, R., Scharf, A., Rodgers, L., Mackin, C. 2004. "Motivating Employee Owners in ESOP Firms: Human Resource Policies and Company Performance.” In Virginie Perotin and Andrew Robinson, eds., Advances in the Economic Analysis of Participatory and Self-managed Firms, Vol. 8. Greenwich, CN: JAI Press, 2004.

Laffont, J., \& Martimort, D. 2002. The Theory of Incentives: The Principal-Agent Model. Princeton, N.J.: Princeton University Press.

Lafley, A.G., \& Sellers, P. 2005. “It was a no-brainer,” Fortune, , February 21, 151(3): 60-64.

Leonard-Barton, D. 1992. "Core Capabilities and Core Rigidities: A Paradox in Managing New Product Development,” Strategic Management Journal, 13: 363-380.

Lepak, D. P., Liao, H., Chung, Y., \& Harden, E.E. 2006. “A conceptual review of high involvement HR systems in strategic HRM research,” In J. M. (Ed.), Research in Personnel and Human Resource Management, Vol. 25: 217-271. Greenwich, CT: JAI Press. 
Lerner, J., \& Wulf, J. 2006. “Innovation and incentives: Evidence from corporate R\&D,” The Review of Economics and Statistics, Forthcoming.

MacDuffie, J. P. 1995. "Human resource bundles and manufacturing performance: Organizational logic and flexible production systems in the world auto industry," Industrial and Labor Relations Review, 48: 197-221.

Mehr, D. G., \& Shaver, P. R. 1996. “Goal structures in creating motivation,” Journal of Creative Behavior, 30: 77-104.

Michigan Governor Talks Design. 2006. Business Week, March 1

Mumford, M. 2000. “Managing Creative People: Strategies and Tactics for Innovation,” $\underline{\text { Human }}$ Resource Management Review, 10: 317.

Oldham, G. R. 2003. "Stimulating and supporting creativity in organizations.” In S. E. In Jackson, Hitt, M.A., \& DeNisi, A. S. (Ed.), Managing knowledge for sustained competitive advantage: 243-273. San Francisco: Jossey-Bass.

Rummel, A., \& Feinberg, R. 1988. "Cognitive evaluation theory: A meta-analytic review of the literature.” Social Behavior and Personality, 16: 147-164.

Shalley, C. E. 1995. "Effects of coaction, expected evaluation, and goal setting on creativity and productivity," Academy of Management Journal, 38: 483-503.

Sobel, M. E. 1982. "Asymptotic intervals for indirect effects in structural equations models.” In S. Leinhart (Ed.), Sociological Methodology: 290-312. San Francisco: Jossey-Bass.

Spector, Paul E. 1992 Summated Rating Scale Construction: An Introduction. Sage, London, Quantitative Applications in Social Sciences, 82

Tang, S. H., \& Hall, V. C. 1995. “The overjustification effect: A meta-analysis,” Applied Cognitive Psychology, 9: 365-404.

Van de Ven, A. H. 1986. "Central problems in the management of innovation,” Management Science, 32: 590-607.

Venkatraman, N. 1989. "The concept of fit in strategy research: Toward verbal and statistical correspondence," Academy of Management Review, 14(3): 423-444.

Wheatley, W. J., Anthony, W. P., \& Maddox, E. N. 1991. "Selecting and training strategic planners with imagination and creativity,” Journal of Creative Behavior, 25: 52-60.

Wiersma, U. J. 1992. "The Effects of Extrinsic Rewards on Intrinsic Motivation: A MetaAnalysis,” Journal of Occupational and Organizational Psychology, 65: 101-114. 
Woodman, R. W., \& Schoenfeldt, L.F. 1989. "Individual differences in creativity: An interactionist perspective.” In J.A. Glover, R.R. Ronning, \& C.R. Reynolds (Eds.), Handbook of Creativity: 77-92. New York: Plenum.

Woodman, R. W., Sawyer, J.E., \& Griffen, R.W. 1993. "Toward a theory of organizational creativity,” Academy of Management Review, 18: 293-321.

Wright, P. M., \& McMahan, G. C. 1992. "Theoretical perspectives for strategic human resource management,” Journal of Management, 18: 295-320.

Zacharatos, A., Barling, J., Iverson, R.D. 2005. "High-Performance Work Systems and Occupational Safety,” Journal of Applied Psychology, 90: 77-93. 


\section{COMPENSATION}

\section{APPENDIX A: \\ Variable definitions and descriptive statistics}

Shared capitalism index: 10-point index with one point profit sharing eligibility, gain sharing eligibility, owning any company stock, holding any stock options, receiving a profit sharing bonus in the past year, receiving a gain sharing bonus in the past year, having an above-median profit- and gain sharing bonus as a percent of pay, having an above-median company stock holding as a percent of pay, receiving a stock option grant in the past year, and having above-median stock option holdings as a percent of pay. Mean=2.59, s.d.=1.85, $\mathrm{n}=27507$.

Profit/gainsharing: If "yes" to receives profits based on "company profits or performance” and/or "Workgroup or department performance” ( $0=$ no, 1=yes). Mean=.74, s.d. $=.441, \mathrm{n}=27676$.

Profit/gainsharing as \% of base pay: If "yes" to receive profits based on "company profits or performance" and/or "Workgroup or department performance”, divided by basepay+overtime, otherwise 0. Mean=.043, s.d.=.090, $\mathrm{n}=27420$

Individual bonus: "In your job are you eligible for any type of performance-based pay, such as individual or group bonuses, or any type of profit-sharing? What does the size of these performance-based payments depend on? Individual performance" ( $0=$ no, $1=y e s)$. Mean=.140, s.d.=.343, $\mathrm{n}=27676$

Individual bonus as \% of pay: If "yes" to individual bonus, answer to "What was the approximate total dollar value of the payment(s) you received [in the most recent year of bonuses]?" divided by basepay+overtime, otherwise 0 . Mean=.013, s.d. $=.064, n=27609$

Stock options: "Do you currently hold any of this company's stock options (vested or unvested)?” (0=no, $1=$ yes $)$. Mean=.03, s.d. $=.179, \mathrm{n}=27816$

Stock options as \% of pay: If "yes" to "Hold stock options," the sum of answers to questions about value of vested and unvested stock, divided by basepay+overtime, otherwise 0 . Mean=.018, s.d. $=.225, \mathrm{n}=27716$.

Employee ownership: "Employee-owner: own any stock thru ESOP, ESPP, 401k, kept stock after stock option exercise, or open market purchase?” ( $0=$ no, $1=$ yes). Mean=.53, s.d.=.499, $\mathrm{n}=27825$

Employee ownership as \% of pay: If "yes" to employee-owner, the sum of answers to questions about the amount of stock in different plans, divided by basepay+overtime, otherwise 0 . Mean=.227, s.d. $=.476, n=27469$ 


\section{HIGH PERFORMANCE WORK PRACTICES}

High performance work system: Mean of following 6 binary items:

a) "Are you personally involved in any team, committee or task force that addresses issues such as product quality, cost cutting, productivity, health and safety, or other workplace issues?” ( $0=$ no, $1=$ yes $)$

b) In the last 12 months have you received any formal training from your current employer, such as in classes or seminars sponsored by the employer?" ( $0=$ no, $1=y e s)$

c) "How frequently do you participate in a job rotation or cross-training program where you work or are trained on a job with different duties than your regular job?" ( $0=$ never or occasionally, $1=$ frequently)

d) "How effective is your work area of team at selecting the very best people to be part of our team/area?” (based on 1-7 scale, item coded as $0=$ ineffective or neutral (1 to 4), $1=$ effective (5 to 7))

e) "Thinking about the next twelve months, how likely do you think it is that you will lose your job or be laid off?” ( $0=$ very or somewhat likely, $1=$ not very or not at all likely)

f) "How effective is your work area of team at sharing information and ideas with each other?” (based on 1-7 scale, item coded as $0=$ ineffective or neutral (1 to 4), $1=$ effective (5 to 7$)$ )

Index mean=.46, s.d. $=.240, \mathrm{n}=27801$, alpha $=.46$.

High performance work system team: Mean of following items, all measured on a 1-7 scale (1=very ineffective, 4=neutral, 7=very ineffective)

a) "How effective is your work area or team at selecting the very best people to be part of our team/area?”

b) "How effective is your work area or team at setting clear performance goals ?"

c) "How effective is your work area or team at getting training on skills we need to solve customer problems?”

d) "How effective is your work area or team at sharing information and ideas with each other?"

e) "How effective is your work area or team at meeting our customers either in our facilities or theirs?"

f) "How effective is your work area or team at rewarding members of the group for excellent work?"

Index mean=4.36, s.d. $=1.32, \mathrm{n}=27251$, alpha $=.88$

\section{ALIGNMENT}

Alignment: Mean of following items, all measured on a 1-4 scale (1=not at all, 2=very little, $3=$ to some extent, $4=$ to a great extent):

a) "To what extent do you understand your company's overall plan for being successful?”

b) "To what extent do you personally agree with this plan?"

c) "To what extent do you feel that the company is providing you with the information, training, and resources necessary to help achieve the goals of this plan” 
d) "To what extent do you feel that your company's culture encourages you to share your ideas about how to achieve the goals of this plan?”

Index mean $=2.87$, s.d. $=.686, \mathrm{n}=27492$, alpha $=.83$

\section{INNOVATION OUTCOMES}

Culture for Innovation: Mean of following items, all measured on a 1-4 scale (1=never or almost never, $2=$ sometimes, $3=$ often, $4=$ always or almost always)

"How often do the following things occur in your facility?"

a) "Ideas for developing innovative products and services are put forward"

b) "Meaningful time is invested in testing good ideas for innovative products and services"

c) "Innovative ideas are carefully considered and fairly evaluated"

d) "Resources are made available to support and develop a good idea that could lead to an innovative product or service"

e) "People who have an innovative idea receive recognition for it"

f) "People who have an innovative idea receive financial rewards for it"

g) "My ideas for innovative products and services have been taken seriously" Index mean $=2.87$, s.d. $=.626, \mathrm{n}=27067$, alpha $=.86$

Innovative Ideas: Mean of following items, all measured on a 1-4 scale (1=not at all, $2=$ very little, $3=$ to some extent, $4=$ to a great extent)

a) "I would be willing to be more involved in efforts to develop innovative products and services"

b) "I have good ideas for innovative products or services"

c) "I have good ideas for improvements in existing products and services"

Index mean $=2.74$, s.d. $=.731, \mathrm{n}=26939$, alpha $=.83$ 


\section{APPENDIX B: The shared capitalist thermometer index}

As a first step in assessing the relation of shared capitalism to employee outcomes, we constructed a thermometer-style index of shared capitalism. This index assigns one point each when the worker was covered by any of the shared capitalist forms of compensation about which the survey asked, with additional points for recent bonuses or grants, and for large bonuses or stock holdings. For questions with a continuous numeric answer, we gave the item a value of 1 if the respondent had a value greater than the median value. Because there is no natural ordering of shared capitalist systems in the sense that a firm first introduces profit-sharing, then adds employee ownership, and then gain-sharing, the index is not a Guttman scale. It is a simple summated rating (Bartholomew et al, 2002; Bartholomew, 1996), using dichotomous scoring.

In the NBER data there are ten variables in the index, which gives one point each for: profit sharing eligibility, gain sharing eligibility, owning any company stock, holding stock options, receiving a profit sharing bonus in the past year, receiving a gain sharing bonus in the past year, having an above-median profit- and gain sharing bonus as a percent of pay, having an above-median company stock holding as a percent of pay, receiving a stock option grant in the past year, and having above-median stock option holdings (including unvested options if they could be exercised today) as a percent of pay.

Indices of this style have both advantages and disadvantages. On the plus side, they provide a quick and ready measure of the extent of shared capitalist arrangements that makes it easy to compare results across surveys and to summarize the broad thrust of findings. Since our firm surveys covered only firms with some shared capitalist arrangements, the index allows us to differentiate workers with differing degrees of incentive to their firm’s programs. On the negative side, the index treats different programs the same even though they potentially have 
different effects on particular outcomes. It postulates a single scale with equal weights rather than using factor analysis or other statistical modelling to obtain weights for given factors. To deal with these problems, we also estimate the relationship of the outcomes to the different types of shared capitalism, introduced as dummy or continuous variables in regressions. ${ }^{4}$ By comparing the results with the shared capitalism index to the results with the disaggregated measures, we can assess the loss of information due to the amalgamation of the measures into a single index.

Figure B1 shows the distribution of our shared capitalism index in the company analyzed here. Close to three-fourths of employees (74\%) have at least one form of shared capitalism (score of 1 or more). The distribution is non-normal, with only $5 \%$ of workers having scores of 6 or greater. The mean score of the index is 2.47 . For our purposes there is sufficient variation in the index to differentiate the extent of the shared capitalist "treatment" on workers.

\footnotetext{
${ }^{4}$ There are statistical techniques to deal with the formation of latent variable indices from questions of the sort that we are amalgamating into a single summated rating. See Bartholomew et al. (2002) and Spector (1992).
} 
FIGURE 1

Innovation culture, shared capitalism, and high performance work systems

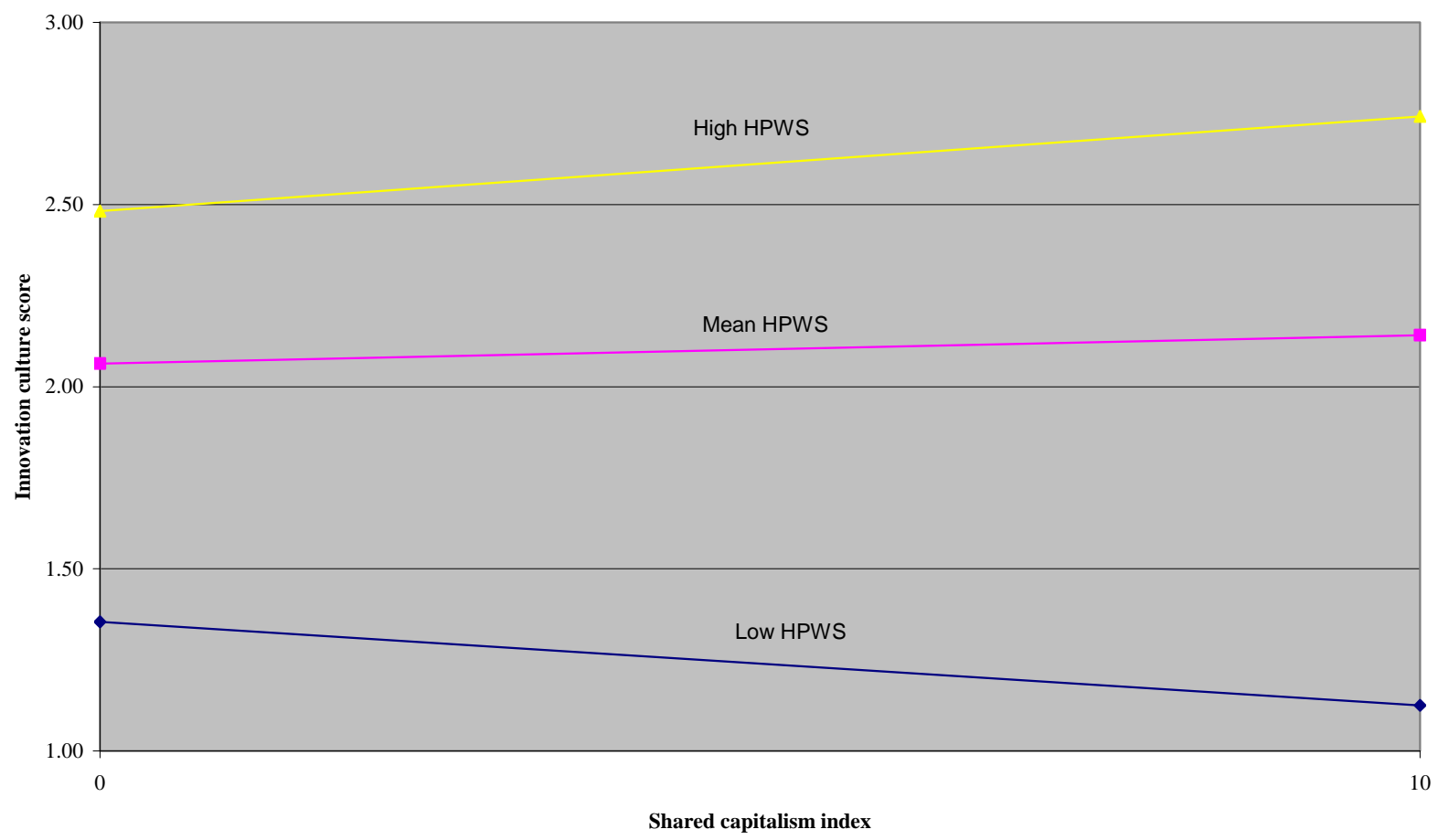

FIGURE 2

Innovation ideas, shared capitalism, and high performance work systems

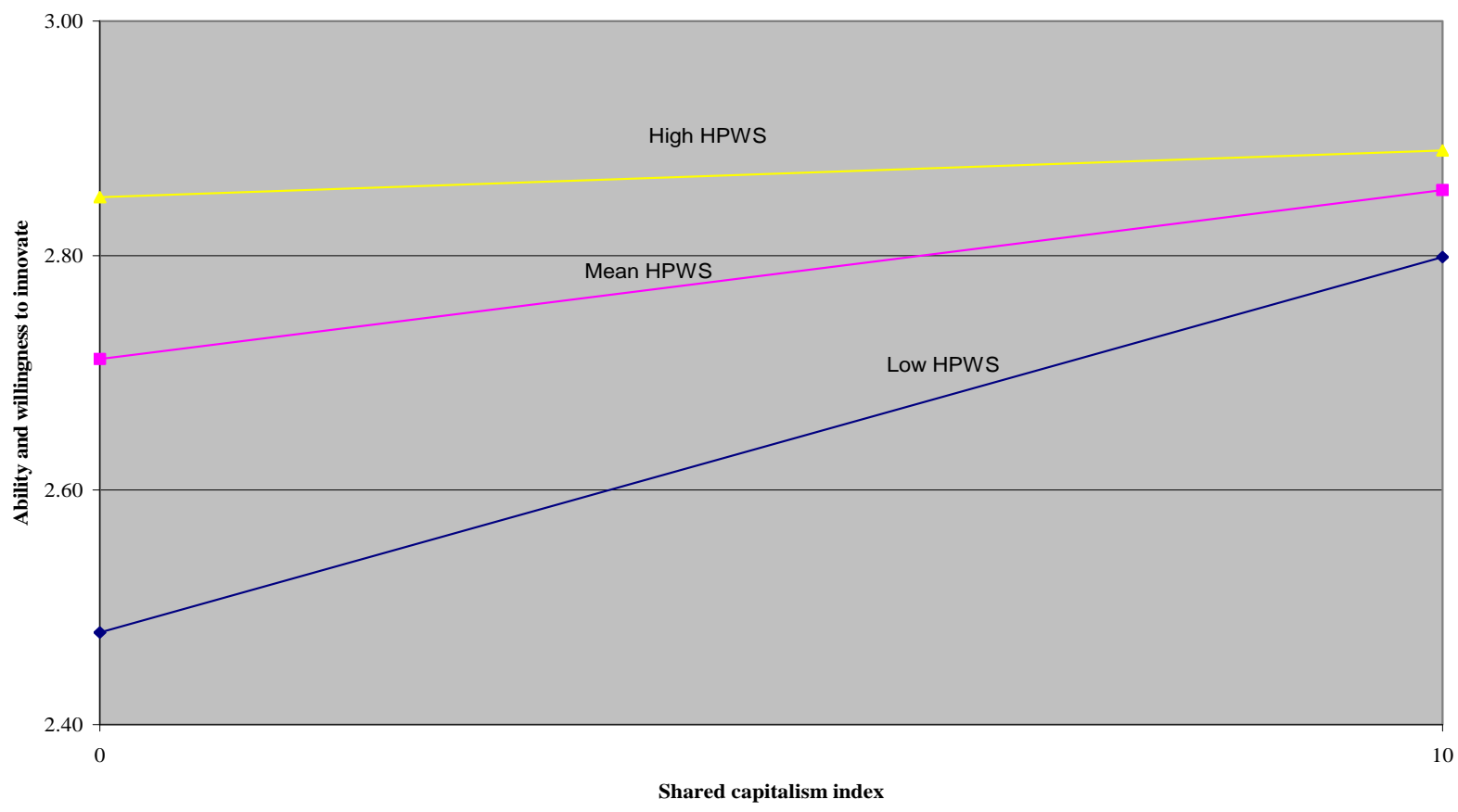




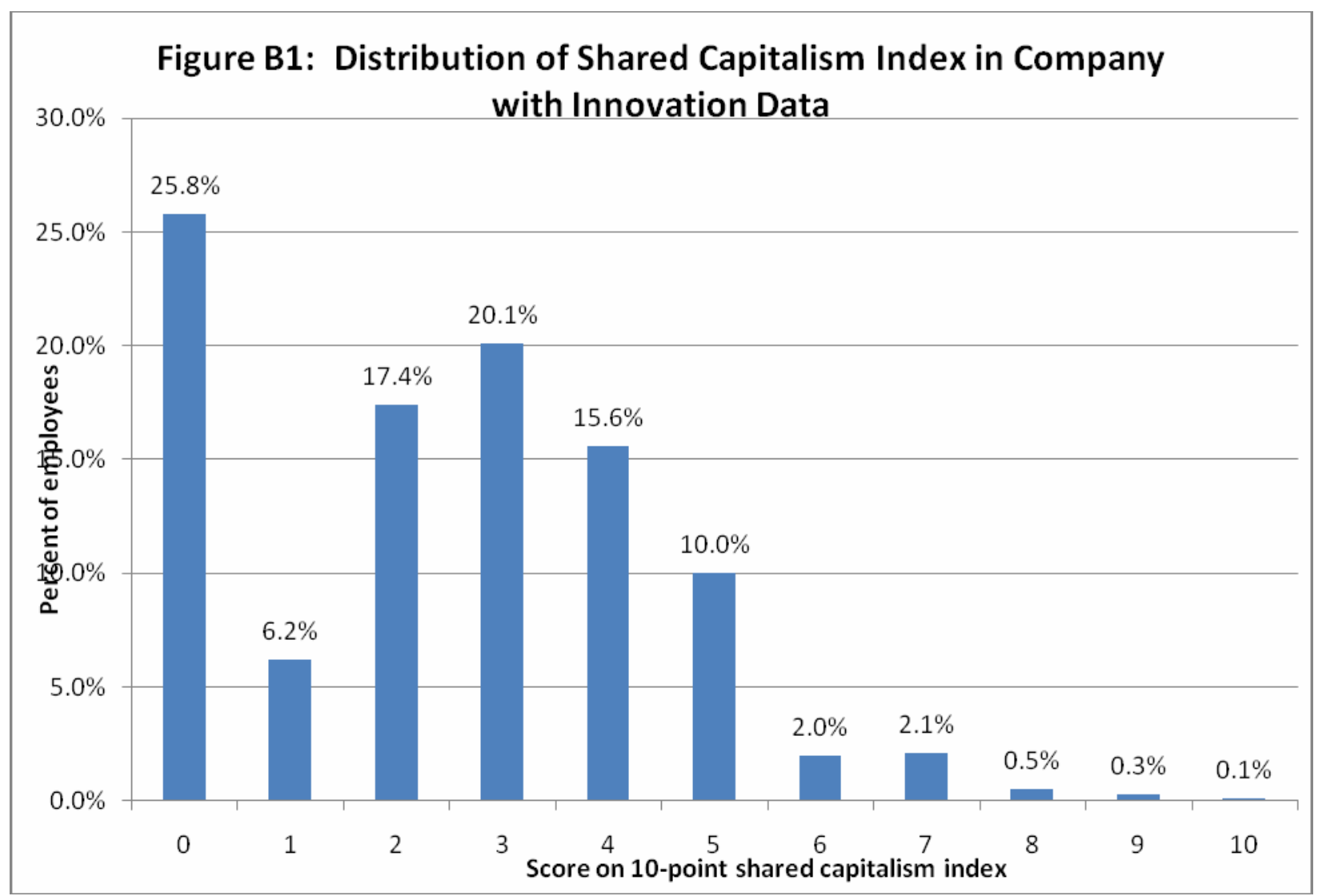


TABLE 1

Predicting a Culture for Innovation

\begin{tabular}{|c|c|c|c|c|c|c|c|c|c|c|c|c|c|c|c|c|c|c|}
\hline \multirow{2}{*}{$\begin{array}{l}\text { Independent Variables } \\
\text { Shared Capitalism Index }\end{array}$} & \multicolumn{3}{|c|}{ Model 1} & \multicolumn{3}{|c|}{ Model 2} & \multicolumn{3}{|c|}{ Model 3} & \multicolumn{3}{|c|}{ Model 4} & \multicolumn{3}{|c|}{ Model 5} & \multicolumn{3}{|c|}{ Model 6} \\
\hline & 0.013 & $(0.003)$ & $\star \star \star *$ & & & & 0.000 & $(0.003)$ & & & & & 0.011 & $(0.003)$ & 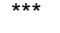 & & & \\
\hline \multicolumn{19}{|l|}{ Bonuses } \\
\hline Profit/gainsharing & & & & -0.008 & $(0.013)$ & & & & & -0.038 & $(0.012)$ & *** & & & & 0.009 & $(0.012)$ & \\
\hline Profit/gainsharing as \% of base pay & & & & 0.291 & $(0.070)$ & $\star \star \star *$ & & & & 0.174 & $(0.067)$ & *** & & & & 0.176 & $(0.065)$ & *** \\
\hline Individual bonus & & & & 0.071 & $(0.017)$ & 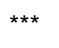 & & & & 0.042 & $(0.017)$ & ** & & & & 0.037 & $(0.016)$ & ** \\
\hline Indiv. bonus as \% of base pay & & & & 0.007 & $(0.102)$ & & & & & 0.064 & $(0.098)$ & & & & & 0.043 & $(0.095)$ & \\
\hline \multicolumn{19}{|l|}{ Employee ownership } \\
\hline Any employee ownership & & & & 0.039 & $(0.012)$ & $* * *$ & & & & 0.023 & $(0.011)$ & ** & & & & 0.027 & $(0.011)$ & ** \\
\hline Employee-owned stock as \% of pay & & & & -0.005 & $(0.010)$ & & & & & -0.010 & $(0.010)$ & & & & & 0.000 & $(0.010)$ & \\
\hline \multicolumn{19}{|l|}{ Stock options } \\
\hline Stock option holding & & & & 0.031 & $(0.031)$ & & & & & 0.039 & $(0.029)$ & & & & & 0.015 & $(0.028)$ & \\
\hline Stock option value as \% of base pay & & & & 0.045 & $(0.031)$ & & & & & 0.055 & $(0.029)$ & * & & & & 0.038 & $(0.029)$ & \\
\hline \multicolumn{19}{|l|}{ High Performance Work Policies } \\
\hline HPWS & & & & & & & 0.806 & $(0.016)$ & *** & 0.802 & $(0.016)$ & *** & & & & & & \\
\hline HPWST & & & & & & & & & & & & & 0.180 & $(0.003)$ & $\star \star \star ~$ & 0.179 & $(0.003)$ & *** \\
\hline $\mathrm{n}$ & 26364 & & & 25832 & & & 26361 & & & 25830 & & & 25977 & & & 25458 & & \\
\hline Adjusted R-sq & 0.054 & & & 0.058 & & & 0.134 & & & 0.137 & & & 0.184 & & & 0.186 & & \\
\hline
\end{tabular}

${ }^{*} \mathrm{p}<.10{ }^{* *} \mathrm{p}<.05{ }^{* * *} \mathrm{p}<.01$ (s.e. in parentheses)

$\wedge$ All regressions include controls for country (22 dummies), occupation (5 dummies), mgt. level (3 dummies), hourly pay status, supervisory status, tenure in years,

hours worked per week, union status, age, gender, marital status (2 dummies), family size, college graduate, graduate degree, number of kids,

race (4 dummies), disability status, In(fixed pay), and company fixed effects. 
TABLE 2

Predicting Innovative Idea

\begin{tabular}{|c|c|c|c|c|c|c|c|c|c|c|c|c|c|c|c|c|c|c|}
\hline \multirow{2}{*}{$\begin{array}{l}\text { Independent Variable } \\
\text { Shared Capitalism Index }\end{array}$} & \multicolumn{3}{|c|}{ Model 1} & \multicolumn{3}{|c|}{ Model 2} & \multicolumn{3}{|c|}{ Model 3} & \multicolumn{3}{|c|}{ Model 4} & \multicolumn{3}{|c|}{ Model 5} & \multicolumn{3}{|c|}{ Model 6} \\
\hline & 0.012 & $(0.003)$ & *** & & & & 0.006 & $(0.003)$ & $\star \star *$ & & & & 0.012 & $(0.003)$ & $* \star *$ & & & \\
\hline \multicolumn{19}{|l|}{ Bonuses } \\
\hline Profit/gainsharing & & & & -0.027 & $(0.014)$ & * & & & & -0.039 & $(0.014)$ & 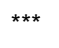 & & & & -0.020 & $(0.014)$ & \\
\hline Profit/gainsharing as \% of base pay & & & & -0.005 & $(0.078)$ & & & & & -0.057 & $(0.078)$ & & & & & -0.032 & $(0.078)$ & \\
\hline Individual bonus & & & & 0.040 & $(0.020)$ & ** & & & & 0.027 & $(0.019)$ & & & & & 0.033 & $(0.019)$ & * \\
\hline Indiv. bonus as \% of base pay & & & & 0.221 & $(0.114)$ & * & & & & 0.248 & $(0.114)$ & $\star \star$ & & & & 0.224 & $(0.114)$ & ** \\
\hline \multicolumn{19}{|l|}{ Employee ownership } \\
\hline Any employee ownership & & & & 0.072 & $(0.013)$ & 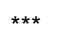 & & & & 0.065 & $(0.013)$ & $\star \star \star *$ & & & & 0.070 & $(0.013)$ & $* \star \star$ \\
\hline Employee-owned stock as \% of pay & & & & 0.008 & $(0.011)$ & & & & & 0.005 & $(0.011)$ & & & & & 0.009 & $(0.011)$ & \\
\hline \multicolumn{19}{|l|}{ Stock options } \\
\hline Stock option holding & & & & -0.026 & $(0.034)$ & & & & & -0.022 & $(0.034)$ & & & & & -0.028 & $(0.034)$ & \\
\hline Stock option value as \% of base pay & & & & -0.012 & $(0.034)$ & & & & & -0.009 & $(0.034)$ & & & & & -0.018 & $(0.034)$ & \\
\hline \multicolumn{19}{|l|}{ High Performance Work Policies } \\
\hline HPWS & & & & & & & 0.350 & $(0.019)$ & 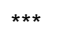 & 0.347 & $(0.019)$ & 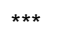 & & & & & & \\
\hline HPWST & & & & & & & & & & & & & 0.042 & $(0.003)$ & $\star \star * \star$ & 0.041 & $(0.003)$ & $* * *$ \\
\hline $\mathrm{n}$ & 26252 & & & 25728 & & & 26249 & & & 25726 & & & 25875 & & & 25362 & & \\
\hline Adjusted R-sq & 0.146 & & & 0.148 & & & 0.156 & & & 0.158 & & & 0.149 & & & 0.151 & & \\
\hline
\end{tabular}

${ }^{*} \mathrm{p}<.10{ }^{* *} \mathrm{p}<.05{ }^{* * *} \mathrm{p}<.01$ (s.e. in parentheses)

^ All regressions include controls for country (22 dummies), occupation (5 dummies), mgt. level (3 dummies), hourly pay status, supervisory status, tenure in years, hours worked per week, union status, age, gender, marital status (2 dummies), family size, college graduate, graduate degree, number of kids,

race (4 dummies), disability status, In(fixed pay), and company fixed effects. 
TABLE 3

Interactions Between Shared Capitalism and High Performance Work Policies in Predicting Innovation Outcomes

\begin{tabular}{|c|c|c|c|c|c|c|c|c|c|c|c|c|}
\hline \multirow{2}{*}{$\begin{array}{l}\text { Independent Variable } \\
\text { Capitalism Index }\end{array}$} & \multicolumn{6}{|c|}{$\underline{\text { Culture for Innovation }}$} & \multicolumn{6}{|c|}{$\underline{\text { Innovative Ideas }}$} \\
\hline & -0.007 & $(0.005)$ & & -0.023 & $(0.007)$ & *** & 0.028 & $(0.006)$ & *** & 0.032 & $(0.009)$ & *** \\
\hline HPWS & 0.768 & $(0.027)$ & $\star * \star$ & & & & 0.463 & $(0.031)$ & $* \star \star$ & & & \\
\hline HPWST & & & & 0.161 & $(0.005)$ & *** & & & & 0.053 & $(0.006)$ & $* * *$ \\
\hline *HPWS & 0.015 & $(0.009)$ & * & & & & -0.045 & $(0.010)$ & $* * *$ & & & \\
\hline${ }^{*} \mathrm{HPWST}$ & & & & 0.007 & $(0.002)$ & *** & & & & -0.004 & $(0.002)$ & ** \\
\hline $\mathrm{n}$ & 26361 & & & 25977 & & & 26250 & & & 25875 & & \\
\hline
\end{tabular}

${ }^{*} \mathrm{p}<.10 * * \mathrm{p}<.05 * * \star \mathrm{p}<.01$ (s.e. in parentheses)

$\wedge$ All regressions include controls for country (22 dummies), occupation ( 5 dummies), mgt. level (3 dummies), hourly pay status, supervisory status, tenure in years, hours worked per week, union status, age, gender, marital status (2 dummies), family size, college graduate, graduate degree, number of kids, race (4 dummies), disability status, In(fixed pay), and company fixed effects. 
TABLE 4

Predicting Employee Alignment with Company Strategy

\begin{tabular}{|c|c|c|c|c|c|c|c|c|c|c|c|c|c|c|c|c|c|c|}
\hline \multirow{2}{*}{$\begin{array}{l}\text { Independent Variable } \\
\text { Shared Capitalism Index }\end{array}$} & \multicolumn{3}{|c|}{ Model 1} & \multicolumn{3}{|c|}{ Model 2} & \multicolumn{3}{|c|}{ Model 3} & \multicolumn{3}{|c|}{ Model 4} & \multicolumn{3}{|c|}{ Model 5} & \multicolumn{3}{|c|}{ Model 6} \\
\hline & 0.010 & $(0.003)$ & $\star \star * *$ & & & & 0.014 & $(0.005)$ & $* \star *$ & 0.024 & $(0.003)$ & $\star \star \star$ & & & & 0.009 & $(0.007)$ & \\
\hline \multicolumn{19}{|l|}{ Bonuses } \\
\hline Profit/gainsharing & & & & 0.016 & $(0.013)$ & & & & & & & & 0.075 & $(0.012)$ & $\star \star \star ~$ & & & \\
\hline Profit/gainsharing as \% of base pay & & & & 0.118 & $(0.070)$ & * & & & & & & & 0.139 & $(0.068)$ & & & & \\
\hline Individual bonus & & & & 0.053 & $(0.017)$ & $\star \star * *$ & & & & & & & 0.050 & $(0.017)$ & $\star *$ & & & \\
\hline Indiv. bonus as \% of base pay & & & & 0.058 & $(0.101)$ & & & & & & & & 0.012 & $(0.097)$ & & & & \\
\hline \multicolumn{19}{|l|}{ Employee ownership } \\
\hline Any employee ownership & & & & 0.009 & $(0.012)$ & & & & & & & & 0.017 & $(0.011)$ & & & & \\
\hline Employee-owned stock as \% of pay & & & & 0.011 & $(0.010)$ & & & & & & & & 0.022 & $(0.010)$ & ** & & & \\
\hline \multicolumn{19}{|l|}{ Stock options } \\
\hline Stock option holding & & & & 0.070 & $(0.031)$ & ** & & & & & & & 0.035 & $(0.030)$ & & & & \\
\hline Stock option value as \% of base pay & & & & 0.021 & $(0.032)$ & & & & & & & & 0.008 & $(0.031)$ & & & & \\
\hline \multicolumn{19}{|l|}{ High Performance Work Policies } \\
\hline HPWS & 1.085 & $(0.017)$ & $* * *$ & 1.081 & $(0.017)$ & $* * *$ & 1.106 & $(0.028)$ & $* * *$ & & & & & & & & & \\
\hline HPWST & & & & & & & & & & 0.230 & $(0.003)$ & $* * *$ & 0.230 & $(0.003)$ & $\star * \star *$ & 0.222 & $(0.005)$ & *** \\
\hline \multicolumn{19}{|l|}{ Shared Capitalism Index } \\
\hline * HPWS & & & & & & & -0.008 & $(0.009)$ & & & & & & & & & & \\
\hline * HPWST & & & & & & & & & & & & & & & & 0.003 & $(0.002)$ & ** \\
\hline $\mathrm{n}$ & 26787 & & & 26243 & & & 26787 & & & 26348 & & & 25819 & & & 26348 & & \\
\hline Adjusted R-sq & 0.220 & & & 0.221 & & & 0.220 & & & 0.275 & & & 0.275 & & & 0.275 & & \\
\hline
\end{tabular}

${ }^{*} p<.10 * * p<.05 * * *<<.01$ (s.e. in parentheses)

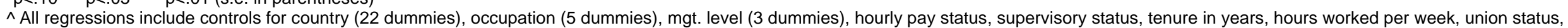

age, gender, marital status (2 dummies), family size, college graduate, graduate degree, number of kids, race (4 dummies), disability status, In(fixed pay), and company fixed effects. 
TABLE 5

Mediating Role of Alignment in Predicting a Culture for Innovation

\begin{tabular}{|c|c|c|c|c|c|c|c|c|c|c|c|c|c|c|c|c|c|c|}
\hline \multirow{2}{*}{$\begin{array}{c}\text { Independent } \\
\text { Variable }\end{array}$} & \multicolumn{3}{|c|}{$\begin{array}{c}\text { Innovative } \\
\text { Environment }\end{array}$} & \multicolumn{3}{|c|}{ Alignment } & \multicolumn{3}{|c|}{$\begin{array}{c}\text { Innovative } \\
\text { Environment }\end{array}$} & \multicolumn{3}{|c|}{$\begin{array}{c}\text { Innovative } \\
\text { Environment }\end{array}$} & \multicolumn{3}{|c|}{ Alignment } & \multicolumn{3}{|c|}{$\begin{array}{c}\text { Innovative } \\
\text { Environment } \\
\end{array}$} \\
\hline & 0.000 & $(0.003)$ & & 0.010 & $(0.003)$ & $\star * *$ & -0.002 & $(0.002)$ & & 0.011 & $(0.003)$ & $\star \star \star ~$ & 0.024 & $(0.003)$ & $* \star *$ & 0.005 & $(0.002)$ & * \\
\hline \multicolumn{19}{|l|}{$\begin{array}{l}\text { High Performance Work } \\
\text { Policies }\end{array}$} \\
\hline HPWS & 0.806 & $(0.016)$ & $\star \star *$ & 1.085 & $(0.017)$ & $\star * *$ & 0.446 & $(0.017)$ & $* * *$ & & & & & & & & & \\
\hline HPWST & & & & & & & & & & 0.180 & $(0.003)$ & $\star \star \star ~$ & 0.230 & $(0.003)$ & 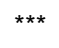 & 0.117 & $(0.003)$ & 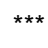 \\
\hline Alignment & & & & & & & 0.313 & $(0.006)$ & $* \star *$ & & & & & & & 0.271 & $(0.006)$ & *** \\
\hline $\mathrm{n}$ & 26361 & & & 26787 & & & 26145 & & & 25976 & & & 26347 & & & & & \\
\hline Adjusted R-sq & 0.134 & & & 0.220 & & & 0.237 & & & 0.184 & & & 0.275 & & & & & \\
\hline
\end{tabular}

Sobel Test HPWS: $40.39(p=.000)$

Sobel Test Shared Capitalism: $7.88(p=.000)$

Sobel Test HPWST: $38.92(p=.000)$ 
TABLE 6

Mediating Role of Alignment in Predicting Innovative Ideas

\begin{tabular}{|c|c|c|c|c|c|c|c|c|c|c|c|c|c|c|c|c|c|c|}
\hline \multirow{3}{*}{$\begin{array}{l}\text { Independent Variable } \\
\text { Shared Capitalism Index }\end{array}$} & \multirow{2}{*}{\multicolumn{3}{|c|}{$\begin{array}{l}\frac{\text { Innovative }}{\underline{\text { Ideas }}} \\
\text { Model 1 }\end{array}$}} & \multirow{2}{*}{\multicolumn{3}{|c|}{$\begin{array}{l}\text { Alignment } \\
\text { Model } 2 \\
\end{array}$}} & \multirow{2}{*}{\multicolumn{3}{|c|}{$\begin{array}{l}\frac{\text { Innovative }}{\underline{\text { Ideas }}} \\
\text { Model } 3\end{array}$}} & \multirow{2}{*}{\multicolumn{3}{|c|}{$\begin{array}{l}\frac{\text { Innovative }}{\underline{\text { Ideas }}} \\
\text { Model } 4\end{array}$}} & \multirow{2}{*}{\multicolumn{3}{|c|}{$\begin{array}{l}\text { Alignment } \\
\text { Model } 5\end{array}$}} & \multirow{2}{*}{\multicolumn{3}{|c|}{$\begin{array}{c}\frac{\text { Innovative }}{\underline{\text { Ideas }}} \\
\text { Model } 6\end{array}$}} \\
\hline & & & & & & & & & & & & & & & & & & \\
\hline & 0.006 & $(0.003)$ & ** & 0.010 & $(0.003)$ & $\star \star \star \star ~$ & 0.006 & $(0.003)$ & ** & 0.012 & $(0.003)$ & $* \star \star$ & 0.024 & $(0.003)$ & $\star \star \star *$ & 0.011 & $(0.003)$ & *** \\
\hline \multicolumn{19}{|l|}{ High Performance Work Policies } \\
\hline HPWS & 0.350 & $(0.019)$ & $* \star *$ & 1.085 & $(0.017)$ & $\star \star \star *$ & 0.311 & $(0.020)$ & $* \star \star$ & & & & & & & & & \\
\hline HPWST & & & & & & & & & & 0.042 & $(0.003)$ & 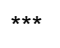 & 0.230 & $(0.003)$ & $\star \star \star *$ & 0.031 & $(0.004)$ & *** \\
\hline Alignment & & & & & & & 0.036 & $(0.007)$ & $\star \star \star ~$ & & & & & & & 0.047 & $(0.007)$ & $\star * \star$ \\
\hline $\mathrm{n}$ & 26250 & & & 26786 & & & 26039 & & & 25875 & & & 26347 & & & 25703 & & \\
\hline Adjusted R-sq & 0.156 & & & 0.220 & & & 0.157 & & & 0.149 & & & 0.275 & & & 0.151 & & \\
\hline
\end{tabular}

* $p<.10$ ** $p<.05 * * * p<.01$ (s.e. in parentheses)

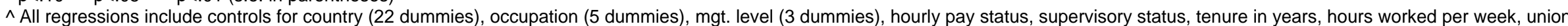
status, age, gender, marital status ( 2 dummies), family size, college graduate, graduate degree, number of kids, race (4 dummies), disability status, In(fixed pay), and company fixed effects.

Sobel Test HPWS: $5.13(p=.000)$

Sobel Test Shared Capitalism: $5.14(p=.000)$

Sobel Test HPWTS: $6.69(p=.000)$ 